\title{
Multigenerational Perspectives on Coping with the Holocaust Experience: An Attachment Perspective for Understanding the Developmental Sequelae of Trauma across Generations
}

\author{
Dan Bar-On ${ }^{1}$, Jeanette Eland ${ }^{2,3}$ Rolf J. Kleber ${ }^{2,3}$, Robert \\ $\mathrm{Krell}^{4}$, Yael Moore ${ }^{1}$, Abraham Sagi ${ }^{5}$, Erin Soriano ${ }^{4}$, Peter \\ Suedfeld $^{4}$, Peter G. van der Velden ${ }^{2}$, Marinus H. van \\ IJzendoorn $^{6}$ \\ ${ }^{1}$ Ben-Gurion University of the Negev, Israel \\ ${ }^{2}$ Institute for Psychotrauma, The Netherlands \\ ${ }^{3}$ Utrecht University, The Netherlands \\ ${ }^{4}$ University of British Columbia, Vancouver, Canada \\ ${ }^{5}$ University of Haifa, Israel \\ ${ }^{6}$ Leiden University, The Netherlands
}

In this paper, we advance a new approach to the intergenerational transmission of Holocaust experiences, by focusing on attachment theory. The approach is used as a framework for interpretation of the results of three studies on Holocaust survivors and their offspring, from different countries (The Netherlands, Canada, and Israel), and based on different conceptual approaches and methods of data collection (quantitative as well as qualitative).

Requests for reprints should be sent to either Dr Abraham Sagi, Center for the Study of Child Development, University of Haifa, Haifa 31905, Israel, or Dr Marinus Van IJzendoorn, Center for Child and Family Studies, Leiden University, P.O. Box 9555, NL-2300RB Leiden, The Netherlands.

Author names are ordered alphabetically. The paper consists of four major parts contributed by four research groups: The Utrecht study was conducted by R.J. Kleber, P.G. van der Velden and J. Eland; the Vancouver study was conducted by R. Krell, P. Suedfeld and E. Soriano; the Beer-Sheva study was conducted by Y. Moore and D. Bar-On. The integration of these projects was initiated and implemented by A. Sagi and M.H. van IJzendoorn (while working on this paper also a Fellow of The Netherlands Institute for Advanced Study in the Humanities and Social Sciences). Together with K.E. Grossmann (Regensburg University), Sagi and Van IJzendoorn are conducting the Three Generation Study of Intergenerational Transmission of Holocaust Experiences funded by the German-Israel Foundation for Research (GIF), that also facilitated work on this paper. Special thanks are due to Ellen Skinner for providing some important ideas.

(C) 1998 The International Society for the Study of Behavioural Development 
The literature is divided with regard to the extent and depth of long-termeffects of the Holocaust. Attachment theory allows the integration of the phenomena of attachment, separation, and loss, which appear to be core concepts in the three studies presented here. The notion of insecure-ambivalent attachment sheds some light on the observed preoccupation with issues of attachment and separation in the second generation. Furthermore, the theme of "the conspiracy of silence" is discussed in the context of attachment disorganisation. Attachment theory transcends the traditional boundaries between clinical and nonclinical interpretations, in stressing the continuous and cumulative nature of favourable and unfavourable child-rearing circumstances. In this context, insecure attachment should be regarded as coping with suboptimal childrearing environments.

This paper focuses on coping of Holocaust survivors and their offspring, and on the enduring effects of traumatic war experiences and loss of parental attachment figures. It uses attachment theory as a conceptual framework for exploring the potential long-term, inter-generational effects of the Holocaust experience. We will summarise the results of three studies from different countries (The Netherlands, Canada, and Israel), employing different approaches to data collection (quantitative as well as qualitative).

\section{HOLOCAUST RESEARCH}

The literature is divided with regard to the extent and depth of long-term effects associated with the Holocaust. In fact, most Holocaust survivors managed to raise families and have become productive and successful in a wide range of activities (Krell, 1993), and some scholars believe that most of the survivors do not manifest serious psychological problems (e.g. Leon, Butcher, Kleinman, Goldberg, \& Almagor, 1981). However, others argue that the Holocaust had a profound effect, leaving many survivors with difficulties including chronic anxiety and depression (Niederland, 1968) or personality inhibitions (Dor-Shav, 1978), as well as marital relationships which have been referred to as "despair marriages" (Danieli, 1980). A negative picture is provided by clinicians who are engaged in therapeutic work with Holocaust survivors, but when it involves research, the picture appears to be less clear (Rieck, 1994; Rieck \& Eitinger, 1983). It is unclear whether in the more controlled studies the instruments were sensitive enough to test the effects found in therapy, or whether the clinical reports are selectively biased. The clinical case-studies may also have included Holocaust survivors who were least successful in coping with their traumatic experiences. Non-Holocaust-related research provides consistent evidence that people who undergo extreme stress are often able to cope rather well under normal circumstances but they are left more vulnerable and more 
sensitive to future adversity (Parkes, 1991; Raphael,1986; Silver \& Wortman, 1980).

Some reviews of empirical studies into the consequences of extremeevents show that about $20-30 \%$ of all victims have to deal with long-term mental disorders (Brom, Kleber, \& Hofman, 1993). It has not been shown, however, that all or even most people involved in such events will develop disorders (Solkoff, 1992). The link between extreme life events and subsequent disorders, such as post-traumatic stress disorders (PTSD) is not deterministic as is often assumed (McFarlane, 1995). Nevertheless, in a number of war- and military-related studies in Israel, it was suggested that even people who have seemingly overcome these traumatic experiences may become more vulnerable to crises in the future, and in extreme cases might even be engaged in reactivating acute stress responses, following exposure to stimuli that symbolise or remind them of the original traumatic experience (Solomon, Garb, Bleich, \& Grupper, 1987; Solomon, Oppenheimer, Elizur, \& Waysman, 1990). Similar results are reported for Vietnam veterans (Frye \& Stockton, 1982; Goldstein, Van Kammen, Shelly, Miller, \& Van Kammen, 1987), for Korean veterans (Thienes-Hontos, Watson, \& Kucala, 1982), and for prisoners who were kept by the Japanese army during World War II (Goldstein et al., 1987). Along the same lines, there are some recent Holocaust-related studies showing that elderly survivors suffered a considerable emotional distress during the Persian Gulf War, to a larger extent than other subjects (Solomon \& Prager, 1992). Similarly, in a recent sleep study, Holocaust survivors who were defined as less adjusted were found to have a lower sleep efficiency index as compared with a control group or with survivors defined as well adjusted (Lavie \& Kaminer, 1991).

Many publications have dealt with inter-generational transmission of traumatic experiences associated with the Holocaust (Solkoff, 1992). Here, even more, clinical reports on children of Holocaust survivors versus more systematic research paradigms are inconsistent in their findings. Whereas clinical reports emphasise the severity of emotional problems and subsequent transmission of such problems over generations (Barocas \& Barocas, 1980), more systematic and controlled studies have not found any extreme psychopathology, and most subjects have been reported to be within the normal range (Felsen \& Ehrlich, 1990; Leon et al., 1981; Rieck, 1994; Rieck \& Eitinger, 1983; Rose \& Garske, 1987; Sigal \& Weinfeld, 1987; Weiss, O’Connell, \& Siiter, 1986).

In a unique study examining the effects of the war in Lebanon on Israeli soldiers, it was found that those who were second generation to the Holocaust, compared with those without a Holocaust background, exhibited a higher rate of combat reactions two to three years after the war (Solomon, Kotler, \& Mikulincer, 1988). Furthermore, when the pace of recovery from combat reaction was compared between the two groups, it was the Holocaust 
group which recovered more slowly. Inter-generational transmission of this type of post-traumatic stress reaction (i.e. combat reaction) was attributed to secondary traumatisation (Rosenheck \& Nathan, 1985). The Solomon et al. study (1988) is especially important because it presents some systematic evidence for transmission effects across two generations.

Nevertheless, despite these intriguing findings, most studies did not find large differences between the second generation and control subjects with regard to psychopathology. It is possible that the effects of war experiences are manifested in various developmental-socioemotional domains, and not so much in psychopathology per se. The mixed outcomes of different studies seriously question the validity of the psychoanalytic concepts as often used in the clinical literature. The lack of a theoretical framework, which is at the same time supported by solid empirical research, may be another reason for the inconsistent outcomes of Holocaust-related descriptive studies. Attachment theory and its recent research advances provide an appropriate conceptual framework as well as clinically-based research tools to integrate both ideographic and nomothetic approaches (Grossmann, 1986).

\section{ATTACHMENT THEORY}

The main focus of attachment theory is on the making and breaking of relationships and as such it contains descriptions and explanations of determinants and effects of affective bonds between children and their caregivers, and of the separation or loss of attachment figures (Ainsworth, Blehar, Waters, \& Wall, 1978; Bowlby, 1973). According to attachment theory, a primary function of attachment relationships is to serve as a source of security for the infant in situations that induce fear or anxiety in the child. The concept explains the process by which infants establish secure or insecure relationships with their primary care providers. It is assumed that children develop an internal working model of their affective bonds during the first four years of life, that is, they construct a mental representation of socioemotional aspects of the world, of others, of self, and of relationships to others who are special to the individual (Bowlby, 1973, 1984).

In a meta-analysis of the first 18 studies with the new assessment for adult attachment (the Adult Attachment Interview or AAI; George, Kaplan, \& Main, 1985) involving a total of 854 families, Van IJzendoorn (1995) found that in about $75 \%$ of the cases, infant attachment security/insecurity with the parent was predicted on the basis of the security/insecurity of the parents' current mental representations of their childhood attachment experiences (Main, Kaplan, \& Cassidy, 1985). That is, parents with an insecure view of their childhood attachment experiences — even before the birth of their child (Benoit \& Parker, 1994; Fonagy, Steele, \& Steele, 1991; Radojevic, 1992; Ward \& Carlson, 1995)-appeared to build an anxious attachment 
relationship with their infant, as measured through the Strange Situation procedure, a standard observation instrument for assessing the security of attachment relationships for 1 to 2-year-olds (Ainsworth et al., 1978).

In addition, the parent's attachment security has been found to be predictive of behaviour towards the children (Crowell \& Feldman, 1988; Grossmann, Fremmer-Bombik, Rudolph, \& Grossmann, 1988; Ward \& Carlson, 1995). For instance, securely attached mothers, compared with insecure mothers, appeared to show more warmth and supportiveness during a challenging activity and to provide clearer and more helpful assistance which encouraged learning and mastery in their children (for a review, see Van IJzendoorn, 1995). At the same time, insecure mothers-in particular those who are still preoccupied with their own attachment experiencesappear to switch between overprotecting their children and inviting role reversal and parentification on the part of their children. Many parents seem to repeat their childhood attachment experiences in relating to their own children, thus stimulating the transmission of (secure and insecure) attachment across generations.

\section{ATTACHMENT AND TRAUMA}

Recently, a number of studies have focused on the effects of loss or trauma on patterns of infant-mother attachment (Ainsworth \& Eichberg, 1991; Crittenden,1992; Main \&Hesse,1990). The results of these studies seem to be of major importance to the study of the Holocaust. A specific attachment classification has been proposed for cases in which loss or trauma have been experienced (Main \& Goldwyn, 1996)—unresolved mourning/unresolved trauma - a disorientation about attachment experiences owing to lack of resolution of mourning in case of loss of a close attachment figure or owing to lack of resolution of trauma in case of experiencing trauma with a close attachment figure. Similarly, an equivalent category for disorganised infantmother relationships has been identified (Main \& Solomon, 1990)—absence of a coherent strategy to organise attachment behaviour around the attachment figure (Ainsworth \& Eichberg, 1991; Crittenden, 1992; Main \& Hesse, 1990).

Loss- and trauma-related studies have shown a consistent relation between unresolved mourning or trauma on the part of mothers and disorganised infant-mother attachment relationships (for a review, see Van IJzendoorn, 1995). Parents who are unable to monitor their discourse and thoughts about potentially traumatic loss experiences consistently, appear to have children who show a lack of consistent attachment strategy in dealing with their parents' separation and reunion in stressful circumstances. It should be noted that it was the lack of resolution of mourning/trauma, that is, the lack of successful coping, rather than the loss/trauma per se that contributed to this 
relation. It is proposed (Main \& Hesse, 1990) that lack of resolution of mourning/trauma is characterised by parental fear which causes the parent to be perceived by his/her child as being either a frightened model or as directly frightening the child, both of which might promote disorganised behaviour in infants.

The Holocaust entailed the (traumatic) loss of significant others as well as traumatic experiences such as imprisonment, death, the confrontation with a radical reversal of norms and values, disillusionment of returning, and other concomitants of the (pre- and post-) war period (Kleber, Figley, \& Gersons, 1995; Lifton, 1980). Not surprisingly, Holocaust survivors faced difficulties in the resolution process of mourning and in coping with traumatic experiences. Moreover, Keilson (1992) suggested also that many Holocaust survivors experienced additional trauma following the Holocaust, which he referred to as "sequential traumatisation".

Two interrelated sources contributed to survivors' difficulties: (a) their internal emotional state, and (b) the external social circumstances (see the nextsection). Concerning the internal emotional state, it should be noted that the circumstances under which mourning took place were not always normal ones: For many, there had been discrepancies between the time of deathitself and the time of being informed about it. When such a gap existed, it could have caused a delay in the onset of the mourning process. Also, in this context, for many survivors the exact date, location of death, and burial of loved ones remained unknown (Dasberg, 1987). Often, the separation occurred after the children had witnessed a regressive process which took place in their parents who were no longer capable of providing financial security, physical protection, or even psychological support (Kestenberg, 1972, 1980; Wardi, 1990). Being left by a close attachment figure aroused feelings of anger even if the separation was caused by death. Many survivors still seem to maintain anger toward their parents because they were left alone. However, they have difficulty in overtly expressing this anger because of the tragic circumstances under which separation took place and they run the risk of being left with an unresolved mourning process (Klein, 1973).

Many of the surviving children seem to treat their own children as adults, like "memorial candles" — a bridge between past, present, and future, a kind of "transposition into the world of the past" (Wardi, 1990). The parents seem to be dependent on their children and are themselves very anxious and conflictual (Wardi, 1990), and thereby become helpless, emotionally unavailable to appraise as well as to respond to the real emotional needs of their children. This orientation significantly deviates from what Bowlby (1951) believed to be so critical to the healthy development of infants: Physical as well as emotional accessibility which would lead to "felt security" on the part of the infant. In terms of attachment theory, many Holocaust survivors may well fall within the conceptual framework of prolonged 
unresolved loss/trauma. Lack of resolution of mourning might have led the survivors as adults to exhibit frightened/frightening, helpless, and unexpected parental behaviour, hence enhancing the likelihood of a disorganised attachment relationship to develop in the parent's own child. Viewing their children (who may now be parents themselves) as "memorial candles" might have further distorted the mourning process, and might have even increased the process of disorganisation.

\section{THE SOCIAL CONTEXT}

Traumatic experiences may destroy the social system of care, protection, and meaning that surrounds an individual, and may therefore delay or even block the process of mourning. Also, society as a whole may play a role in facilitating or hampering this process, in emphasising the necessity of dealing with the past or in valuing future-oriented perspectives (Kleber, 1995; Kleber et al., 1995). Many survivors might have become part of the "conspiracy of silence" which grew from the survivors' need to forget and to adjust to new social contexts which were not always receptive to the cruel stories of the past. This social context varies according to cultural and historical circumstances of countries in which the survivors started their new lives. For instance, in Western Europe as well as in North America the survivors were confronted with a need to acquire a secure and successful position in a rapidly changing, industrialising society.

In the case of Israel, one might expect a more receptive understanding of the survivors' special need to work through their past experiences. Paradoxically, many survivors experienced the opposite. They were exposed to the "Sabra myth"1 which emphasised strength and courage. At the same time, survivors did not want to be perceived as those associated with the myth of the victims (Yablonka, 1990). These conflicting forces contributed to the survivors' need to restrict their feelings and hence their difficulty in working through the mourning process.

In sum, we have presented an overview of pertinent research on the psychological sequelae of the Holocaust, followed by a brief outline of attachment theory as it pertains to the transmission of insecure parenting and traumatic experiences across generations, and finally a description of the European-American context as well as the Israeli social context to which the Holocaust survivors had to adapt. We propose that an integration of these aspects may provide a conceptual framework for studying the intergenerational transmission of Holocaust experiences, and may facilitate the

\footnotetext{
${ }^{1}$ The lexical definition of a Sabra is a person who was born in Israel. The word 'Sabra' comes from a common thorny bush that has fruit with prickles on the outside and is sweet on the inside. The Sabra had an aura of glory, and it became a national ideal. The Sabras were filled with a deep faith in the supremacy of their lineage (Segev, 1992).
} 
reconciliation of the epidemiological and the clinical approaches which have led to inconsistent findings.

Against this background, the results of three studies on the transmission of Holocaust experiences will be summarised. The first study in The Netherlands - the Utrecht study conducted by Kleber and associates-uses quantitative methods to document the influence of Holocaust experiences on family life and child-rearing patterns of Holocaust survivors, compared with a group of participants who had not experienced the Holocaust. The second project - the Vancouver study performed by Krell, Suedfeld, and Sorianofocuses on child survivors and their children. Employing descriptive methods and case material, they elucidate the successful coping of the first generation with the Holocaust trauma, as well as some of the long-term adverse consequences for the second generation. In the third study - the Beer-Sheva project carried out by Moore and Bar-On-an ideographical and hermeneutic approach is used to describe in depth the case of one representative of the second generation who struggles with conflicting representations of the traumatic family experience and the collective ideal of the Israeli Sabra.

In all three studies attachment-related child-rearing patterns of Holocaust survivors will be disclosed, in particular those contributing to the transmission of insecure-preoccupied representations of attachment. Also, the difficulties in the working through of traumas experienced in the Holocaust for survivors as well as their offspring are emphasised, and will be discussed in the context of disorganised attachment representations.

\section{THE UTRECHT STUDY: THE NETHERLANDS}

The aim of this study was to investigate the psychological and psychopathological consequences of being brought up by Jewish survivors of World War II in The Netherlands (for detailed information see Eland, Van der Velden, Kleber, \& Steinmetz, 1990). A random group of the Jewish "second generation" $(n=30)$ and a random comparison group $(n=30)$ were sampled in the region of Greater Amsterdam (the city of Amsterdam and surroundings). Subjects were born between 1945 and 1970. The participants of the comparison group were matched to those of the Jewish group using age, education, and sex as criteria. All parents of the Jewish group had undergone horrific experiences such as hiding and concentration camps. All parents of the comparison group had experienced the circumstances of World War II in The Netherlands, but no concentration camps, hiding, or resistance activities. The following questions relevant to this paper were addressed:

1. Have the war experiences of the parents affected characteristics of family life and the way the children born after the war were brought up? 
2. Do these war experiences affect the significant social relationships of their grown-up children?

The participants were interviewed and completed several standardised questionnaires. First, the present relationships of the respondent with friends, partner, and parents were explored. Next, childhood recollections of the respondent were examined. Finally, some questions were asked about the extent to which the parents' war experiences were discussed at home and the extent to which such experiences had impact on family life. An additional clinical questionnaire concerned impressions of intrapsychic processes with regard to individual adjustment and family dynamics.

The findings of this study can be summarised as follows (for more details, see Eland et al., 1990). According to the clinical reports, Jewish parents did not demonstrate less affection towards their children than did the parents of the reference group. The children themselves did not think that they received less emotional support from their parents when they had to do something difficult or when they were ill or upset. Children of Jewish war survivors in The Netherlands, however, considered their childhood as characterised by problems with separations in the family, more so than the reference group. Their parents were preoccupied with the many losses in wartime, and therefore became focused on keeping the family together which interfered with separation and individuation of the children. Subjects were asked whether they had the feeling that they knew the most important war experiences of their parents. The children of Jewish war survivors reported that they were not familiar with the details of these experiences. The reference group thought they knew the war past of their parents better. Because war experiences were not discussed in detail in the Jewish families, we may consider the possibility that there was evidence of a "conspiracy of silence".

Some differences between the Jewish and the reference group were also found with regard to overprotection by the parents and to parentification (for the term "parentification", see Main and Goldwyn, 1996). In comparison to the reference group, the Jewish children felt more responsible for their mothers. This feeling of responsibility may also be inferred from the more frequent telephone contacts with their mothers. According to the clinicians, it was clear that the children took over the caring and supporting role of the parents and that the parents were dependent on the child for emotional support. The children experienced their Jewish fathers as excessively committed and overprotective. It is noteworthy that in comparison with the subjects of the reference group, the Jewish children thought that even in adulthood the war experiences influenced their current lives to a greater extent.

At the same time, however, we must not exclude the possibility of an alternative explanation: The differences between the Jewish and the 
reference group may have been due to possible differences between the Jewish and the general Dutch culture, perhaps not entirely related to the Holocaust or the war. It could be the case that Jewish parents tend to be culturally more overprotective even if they spent their entire life in safe places (e.g. the United States). Nevertheless, a controlled study in Israel using a similar design, as the original Dutch study, showed the same differences between offspring of Holocaust survivors and their matched Jewish peers (Brom, Kfir, \& Dasberg, 1994).

\section{THE VANCOUVER STUDY: CANADA}

To learn about child survivors as parents, questionnaires were distributed at two gatherings of child survivors of the Holocaust, one held in Montreal in 1994 and the other in Los Angeles in 1995. Thirty-five responses from the former and twenty-two from the latter have been analysed. In addition, the Los Angeles meeting provided an opportunity to distribute questionnaires to a number of second generation offspring accompanying their survivor parents. A number of interesting themes and patterns, and some intriguing paradoxes, emerged.

The findings revealed that the guiding principles for child rearing involved the importance of teaching respect for and acceptance of others, honesty and sharing, providing an education, providing structure and security, and demonstrating love. The ideas of the children (second generation) of child survivors (first generation) stand in sharp contrast to those of their parents. Two major themes predominate, and when compared with the responses of the parents, pose four paradoxes. One theme concerns the preoccupation of second generation children with the pain experienced by their parents. They remember devoting their early years to pleasing the parents through high achievement in school, bringing home only good news, and avoiding asking questions about the Holocaust for fear of triggering painful memories (i.e. "conspiracy of silence").

A second theme reflects the expectation of children of survivors not being entitled to happiness. Survivors' offspring derive a sort of survivor guilt not only from the perceived injustice of gaining their own enjoyment as a result of their parents' efforts, but they also ask themselves why they should enjoy themselves when so many others, more deserving, could not.

\section{Four Paradoxes}

The combination of childhood preoccupation with parental sadness, plus the belief that one is not entitled to personal happiness, sets the stage for pervasive and persistent feelings of guilt. Many of the second generation 
suffer guilt simply because their circumstances have been so much better than those experienced by their parents (even though they realised that this was what the parents intended for them), and that their improved situation is due to the sacrifices made by the parents. For children of survivors generally, and perhaps of child survivors particularly, life is a matter of unrelenting seriousness. This reaction accompanies not only the expressed pride of the survivor parents in having children, but also their insistence that happiness and joy be an integral part of their offspring's lives. The first paradox, therefore, is that the second generation seems to have received this message quite differently from how the parents perceive to have sent it.

From the remarks of survivors about their parenting approaches, they clearly wanted to raise decent human beings, even more so given their personal experiences of terrible mistreatment. One inherent problem in the message, as it was extended by the parents and received by the second generation, was that the offspring, in their quest to be "decent", came to feel that they must achieve no less than perfection. Therefore, they always felt that they fell short of fulfilling their parents' expectations, even when the parents moderated an initially unrealistic level of aspiration for their child. In many cases, it was perhaps inevitable that the message about what the parents hoped for from their children reflected not only the usual parental ambitions but also the parents' and/or the children's imagination about what might have been accomplished by members of the family who had perished in the Holocaust.

It followed from the parents' own suffering of extreme levels of insecurity that they wished a maximally secure life for their children. In the quest to achieve such security, unfortunately, they frequently provided messages of extreme and imminent danger, and promulgated all kinds of restrictive imperatives. The overprotectiveness accompanying the wish to provide a secure world also made it exceedingly hard for many offspring of survivors to leave home. In part, that accounts for many references in the literature to the difficulties around separation and individuation (Barocas \& Barocas, 1980).

The second paradox follows: The child survivors' offspring often report that they were the recipients of all the material things that could be purchased and learned the importance of such possessions, but were actually taught comparatively little in the way of other values. Although parents thought they were inculcating nonmaterialistic values, the business of their lives and the preoccupation with their work and career often took precedence over all other considerations. This was strengthened among adult survivor parents who were immersed in reconstructing their shattered lives in a demanding social context, and among child survivors by their avid desire to fit into their adopted culture. By the time the parents were able to look up from their work, their children were grown and frequently gone. There is evidence, however, 
that efforts to transmit humanistic values did succeed in many instances (Peskin, 1981).

The third paradox emerges from the fact that, within the framework of clinical experience with therapy groups comprised of children of survivors, there is an emphasis on complaints about earlier parenting. Yet, although complaining about the poor quality or actual absence of parental affect, the relative lack of empathy with their problems, and the consequent problems that they themselves have with affect and empathy, group members point out to each other how obviously humane and human they are, and note the other members' achievements and personal qualities. This may be a direct consequence of a singularly interesting phenomenon. Rarely are the children of survivors praised to their face by the survivor parents. What these children often experience is that the praise meant for them is communicated by survivor parents in conversations with their acquaintances and friends who talk a great deal about their children's accomplishments. In the quest for perfection in their children, the parents are remembered as having praised but rarely, but criticising lavishly. Children of survivors will often state that they are successful in work and relationships despite a flawed upbringing. The likely parental response is to claim that such accomplishments are in fact the result of a good upbringing.

The children of survivors were raised by people who had experienced adversities so profound that they could not fail to become part of the parenting atmosphere; yet their nature and effects were seldom made explicit. Children of survivors therefore received a variety of implicit messages from the past, while trying to live up to the explicit messages of the present. From the parental viewpoint, withholding detailed information about the horrors of the Holocaust seemed crucial to the child's normal development by freeing the child from having to face the burdens of the past. From the child's point of view, the parents and their past life were enveloped in awesome mystery, which prevented the child from understanding the imperatives that derived from the Holocaust background of the parents. This fourth and last paradox is, perhaps, the most pervasive and important one of all.

\section{THE BEER-SHEVA STUDY: ISRAEL}

In a biographical study, Bar-On (1995) asserted that the "untold story" of the past was often transmitted by the survivors with greater intensity from one generation to another than the "told" story. The second generation became sensitive to their parents' needs to keep silent responding with a "double wall". The parents did not tell and the children did not ask. When there was a need to make windows in the wall, as a rule, one side met with the wall of the other. Often, when the story was told (Bar-On, 1995), it seemed that 
conscious or unconscious censorship took place. The second generation also got involved in "censoring" due to the feelings of being overwhelmed by stories of their parents. The stories told by the first generation often minimised the importance of the personal stories by the second generation, as they had not experienced extreme events as their parents had done. Against this background, some illustrations based on a biography of a second generation man will be presented. It touches on the difficulties of connecting to the family history, as compared to the Israeli, Sabra image.

\section{Alon: Second Generation}

Alon was born in 1958 in a northern Israeli city. His mother also was born in Israel. The extended family of Alon's grandmother and grandfather, originally from Galicia and Poland, were all murdered in the Holocaust (except for one cousin). Alon's father was born in Hungary to a Zionist family. At age 13 or 14, he was taken to Auschwitz. Alon's grandfather was also in Auschwitz and was last seen in January 1944. Two of his father's brothers survived. Alon's father arrived in Israel at age 16 and he immediately joined the Hagana (Jewish fighters who were the forerunners of the Israel Defence Forces), then served as an intelligence officer in the standing army. His parents got married in 1957, and Alon was born a year later.

Alon opened the biographical interview with the statement: “... Ah, I will not tell my story in relation to the Holocaust ... but the Holocaust is sure to pop up here and there ...". It might be assumed that Alon guessed what the intention of the interviewer was; perhaps he responded to himself. However, it immediately disclosed his intention to disconnect his life story from that period of his family's history. In addition, Alon was aware, that despite his efforts and desires, the Holocaust existed and might have "popped up" unwittingly. In this way, right from the opening sentence, he demonstrated the difficulty that a native-born Israeli had with confronting the historical past. Alon's narrative presented two separate versions. One version, the relatively covert one, was derived from the historical verification of his family's involvement in the Holocaust. The other version, the more manifest one, was crystallised around his being an Israeli. The interview shows that he had trouble combining them into one integrated story.

At the beginning, Alon related to his father: "I was born in Hadera ... My father, ah, was in the army ... He immigrated when he was young after the Holocaust ..." Alon continued to tell about his father's army career (the Hagana and the standing army). Alon identified his father as being an Israeli "fighter" on the one hand, whereas originally ("he was young"), he was in the Holocaust. Alon wanted, however, to tell his own story within the framework of "a new life", a life that began in Israel. Here we find Alon's attempts to mark his own identity, compared to his father, who must do something to 
become an Israeli: He used the army and its corresponding strength in order to ostensibly change himself into an Israeli. As the text continued, Alon repeatedly presented his "natural" Israeli version.

His manifest narrative crumbled, however, and the Holocaust "pops up" while he did not hide his own excessive agitation: "... now this grandmother was an intellectual type and she had ... a book that she loved very much (he began to laugh) a small black book with pictures of horrors from the Holocaust (he laughed) now (laughed) how did I learn about the Holocaust you may ask... she would take me into bed with her sometimes me and one of my cousins, boys and girls (it is not clear whether he said "one of ours") and she would open up the book and she would turn the pages and cries of oy oy would escape from her throat (a loud laugh) and now, ah, my father was a counsellor in the army officers' course ... (he laughed and I joined in) then, I don't know if all of the officers in this military base would wear hats with visors ... and the Germans (he laughed very hard), the SS and the Wehrmacht also had hats with visors (he did not manage to get out the word because he was laughing so hard) and I didn't (slowly) understand (laughter) it, that is, what I am trying to say is that the matter (quickly) of the army that was also quite important to me, for my father, when I saw him in his uniform and I saw the black and white photographs ... I didn't quite understand-she was whining about the soldiers' actions and these soldiers appeared to me to be positive... and I amnot a psychologist, but, I imagine that this created in me a special way of looking at the Holocaust ... and I liked that book very much I must add ..."

Perhaps the two contradictory experiences were never put together before - that of the Holocaust and that of the fighting Israeli-into such a perplexing text. The story, and especially Alon's laughter, which accompanied his words, represented two opposites, that of the victim and the persecutor. His father, who appeared as an Israeli commander, was suddenly transformed into a NaziSS commander - through the symbolic power of "the hat with visors". This paradoxical condensation demonstrated some of Alon's difficulties in connecting the past to the present.

Israeli society, in the beginning, demanded a heroic text from its members. Behind the myth of the Sabra, however, reside memories of a different kind - that of loss and destruction, of survival and humiliation. When members of the second generation are requested to build their own personal biography, they are liable to place themselves between the enlightened text, the collective one and the "dark" text, that is about past pains and losses. The second generation was forced to move between the dual experiences of the Sabra and the Holocaust survivor, and often they had difficulty constructing their own story within this duality. They had trouble building their independent role and story, neither being dependent nor counter-dependent on that of their parents. 


\section{DISCUSSION}

In this concluding section, we would like to discuss the results of the three studies as they pertain to the framework of attachment. Although the original studies were not designed to address directly attachment issues, they appear to shed light on the interplay between Holocaust experiences and attachment-related concepts. For example, in all three studies one of the emerging themes is the parental overprotection on the part of survivors and the subsequent parentification on the part of their children. In terms of attachment theory, this theme can be discussed in the context of the development of an insecure-ambivalent attachment orientation. Our evaluation consists of three sections. In the first, we focus on the adaptive responses of the Holocaust survivors and their offspring as well as on the psychological costs of this adaptation. We propose that insecure-ambivalent attachment provides a possible description of the observed relationships between survivors and their children. In the next section, the implications of the frequently detected "conspiracy of silence" phenomenon are discussed in terms of the possible absence of an organised attachment strategy, in particular as it relates to lack of resolution of loss or other traumatic experiences. In the last section, we address methodological issues arising from the application of epidemiological and clinical approaches to the complex theme of the Holocaust experiences, and we propose a new, integrative research paradigm related to attachment theory.

\section{Adaptation and its Costs}

The Utrecht study is one of the few studies designed as a comparative study searching for commonalities and differences between the children of Jewish war survivors and a comparison group. One of the major results was that children of Holocaust survivors described their childhood as characterised by problems of separation and individuation in the family. More often than the reference group, their parents were found to be preoccupied with their prior separation and with loss experiences to the extent that they were not able to respond adequately to the separation and individuation needs of their offspring, and were less able to initiate separate activities. The survivors appeared to be more overprotective than their counterparts in the comparison group, and in adulthood their children also felt more responsible for the well-being of their parents, and they remained in touch more frequently. One is reminded, however, that religion is confounded with Holocaust or lack of Holocaust experiences, namely, the Holocaust survivors were Jewish and the comparison group non-Jewish. Therefore, the results should be interpreted cautiously.

Although a comparison group was lacking in the Vancouver study, the picture of the overprotective survivors and role-reversing offspring is 
confirmed. In particular, the second generation complained about continually trying to please their parents, and protecting them against the adversities in their own lives. The children of the survivors felt a pressure to achieve where their parents lacked the opportunities, and at the same time they felt a failure to fulfil the high expectations of their parents. On the one hand, survivors stressed the need to protect their children from an insecure world, whereas on the other, they implicitly "urged" them to be successful. In the Beer-Sheva case-study, the same dialectic between the wish to please the parents, and the failure to accommodate to their high level of aspirations, may be seen.

In attachment theory, this pattern of preoccupied and overprotective parents and role-reversing, and guilty children who remain enmeshed in this primary relationship, has been described as the insecure-ambivalent and preoccupied attachment strategy. As widely stated in the attachment literature (e.g. Ainsworth et al., 1978), the label "insecure" does not necessarily mean clinical disturbance, because many insecure children and adults adapt successfully to the demands of their environment. In fact, Main (1990) characterised the ambivalent strategy as the most adequate response to a less optimal child-rearing environment that does not show the consistent sensitive responsiveness which is necessary in order to facilitate the development of a secure bond between the parent and the child. Insecurity should be considered a risk factor that only in combination with other risk factors might lead to mental distress and disorders (Main, 1996). In nonclinical samples, the ambivalent attachment strategy has beenfound to be associated with a preoccupied mental representation of attachment in the parent (van IJzendoorn, 1995), that is, with a mental state in which angry preoccupation with parental wrongdoing and the firm resolution to be a different parent, predominate the processing of information from the present. Preoccupation with the past leaves too little room for the unbiased perception of the child's needs and emotions, and blocks or hampers a prompt and adequate response to those signals.

The inconsistent responsiveness that follows from this preoccupied state of mind leads to ambivalent attachment in the child who tries to draw attention to his/her own situation and emotions by stressing the need for proximity, and at the same time striving for independence. As a consequence, the child may never feel to have experienced enough emotional proximity, as well as sufficient autonomy in his/her relationship to the parent. The phenomenological similarity between the ambivalent/preoccupied attachment strategy and the second generation impressions of their childrearing experiences may make the seemingly inconsistent epidemiological and clinical results compatible. Insecure-ambivalent attachment does not prevent children from becoming adaptive adults; on the contrary, their ambivalence and related feelings of guilt may constitute a major motivational 
force to be successful and to indeed keep pleasing the parents. The insecurity may, however, leave its marks in at least two ways. First, insecure individuals may often feel distressed and dissatisfied because they remain failing to reach the high standards of their parents, and at the same time they feel unable to change their strong bonds to them. Second, in times of stress they may be more vulnerable to exhibit maladaptive responses because they lack the firm foundation of a secure attachment relationship and they may be liable to similar biases in the processing of information as their parents seem to be. In the Beer-Sheva case, the interview shows us the difficult and distressing emotional reality behind the mask of the successful and adaptive lawyer, still struggling with ambivalent feelings of trying to please his father and to fulfil his expectations, and at the same time erratically striving to reach individual autonomy.

\section{"Conspiracy of Silence" and Unresolved Loss}

A common theme of the three studies is the "conspiracy of silence", that is, the inability of the Holocaust survivors to talk about their traumatic experiences with their own children, and the inability or reluctance of the children to stimulate their parents to communicate openly about the horrific events. In the Utrecht study, the children of the Jewish survivors reported that they were not familiar with the most significant Holocaust experiences of their parents, whereas the comparison group felt they were better informed about their parents' experiences during the war. Despite the methodological confound between religious affiliation (Jewish/non-Jewish) and war experiences (Holocaust/Non-Holocaust), it seems reasonable to assume that Jewish survivors did not talk openly about the Holocaust simply because they had undergone very traumatic experiences, to a much greater extent than the non-Jewish population. The latter, albeit experiencing the war, did not go through the same suffering and horrors that most Jews did in the same country.

In the Vancouver study, the second generation participants said they avoided asking questions about the Holocaust for fear of burdening their parents with painful memories. On the part of the surviving parents, the silence about their traumatic experiences was influenced by the wish to keep their children away from the burden of the past horrors, and to set them free for a more satisfactory and happy future. In the Beer-Sheva study, the "conspiracy of silence" is related to the social context and image of the Sabra who are more interested in the successful adaptation to future social demands than in the disasters of the past. It is also illustrated that the "conspiracy of silence" cannot be total: Other family members may feel more inclined to speak about the past than the parents. Because the second generation participant in the study was (incompletely) informed by his grandmother about his father's experiences in the Holocaust, he could not avoid imagining 
in what way his father survived the horrific events, and became the Sabra-like personality that he later presented to his son. In fact, the case-study shows how small details of the Holocaust experience may affect the second generation pervasively, just because only part of the story is being told and much is left to the imagination. In the Vancouver study, we find behavioural traces of unresolved trauma in the parents that affect the second generation indirectly. For example, participants reported on parental nightmares, on psychotic episodes, and the need for psychiatric help on the part of the parents, all of which required or provoked responses on the part of the children, whether or not the cause of the distress was openly communicated. The responses included the feeling of being paralysed when confronting the mother's behaviour, or having to contact the emergency services under frightening conditions. We argue that especially in the absence of clear-cut and explicit reasons or causes for parental distress, the children might develop disorganised attachment patterns.

Recent attachment studies have shown, for example, that children who experience abuse from their own parents, are confronted with the paradox of their attachment figure being simultaneously both a source of fear as well as the only potential haven of safety. Their response to this unresolvable paradox is the momentary breakdown of a behavioural strategy, such as the freezing or stilling of their behaviour in the presence of the parent (Main \& Solomon, 1990). On a less dramatic level, recent research has also shown that parents struggling with unresolved loss or other trauma may, for example, inadvertently display a frightened facial expression in the presence of the child who is not able to make the causal connection between the loss or trauma and this fright in the parent. Again, the parent creates a paradoxical situation, inducing fear in a child who is dependent on her for his/her feeling of security. Consequently, and especially in stressful situations, the child may not be able to use consistently an organised insecure or secure attachment strategy, and instead demonstrates disorganised attachment behaviours such as bizarre stereotypes. It should be noted that more than half of the abused children exhibited this type of disorganisation (Carlson, Cicchetti, Barnett, \& Braunwald, 1989). Moreover, several studies have shown a strong association between unresolved loss or trauma in parents and disorganised attachment behaviours in their children (van IJzendoorn, 1995). Main and Hesse (1990) proposed that frightened and frightening parental behaviours constitute the mechanism underlying this association. They suggested that unresolved loss or trauma may trigger feelings of fright which would be difficult for the parent to suppress or control, and at the same time impossible for the infant to understand and interpret (for an empirical test, see Schuengel, BakermansKranenburg, \& Van IJzendoorn, 1997).

Such a paradox is evident, for example, in the Vancouver study. Many Holocaust survivors who experienced extremely frightening traumatic 
events, seemed to strive for maximum security in their children's lives. Even the children's exposure to minor risks appeared to have provoked exaggerated responses of fear in the parents, which from an attachment perspective, can be seen as parents who unintentionally transmitted disorganising messages of imminent danger. Thus, instead of gaining comfort and security from the parent, the child had to deal with a frightened/ frightening parent who left the child in a state of confusion about the reasons for his/her behaviour. The confusion might even reach a stage in which the child cannot differentiate between cause and effect, or victim and victimiser. The Beer-Sheva case illustrates dramatically this confusion in Alon who seems unable to keep separate the image of his father as an Israeli military officer and as a Holocaust survivor who suffered the atrocities of the Nazi concentration camps. Alon's style of speech and nonverbal behaviour is indeed telling. In attachment theory, unresolved loss or trauma is derived from an unconscious failure to monitor coherently the discourse about the traumatic events resulting, for example, in confused statements concerning past and present, as if the trauma is being relived. The Beer-Sheva interview provides ample evidence of intrusion of past events into current speech, and of the lack of control of emotional expressions during the discourse. It is exactly this type of incoherence that in the Adult Attachment Interview may lead to the unresolved classification (Main \& Goldwyn, 1996).

\section{Integrating the Epidemiological and Clinical- Qualitative Perspectives}

Before we integrate the various findings, we want to emphasise the post-hoc nature of our interpretations. The three studies comprise retrospective data and they were already designed and implemented before we began to explore the relevance of attachment theory in integrating and explaining the common themes as they emerge from the findings. Also, studying the effects of the Holocaust experience on the survivors and their offspring, we are faced with the limitations of our tools and designs.

In this complicated area, the survey approach might provide a preliminary idea of the presence of the phenomena in a large population. At the same time, this approach is limited in its capacity to capture the conscious or unconscious feelings and coping processes. It is probably the case-study approach that is better geared to reveal multiple layers of emotions and meanings. Accordingly, the participant is allowed to explore freely and reflect on the impact of the traumatic experiences on his/her life, and to assist the researcher in making sense of this complex issue. Obviously, the case-study does not leave room for rigorous testing and generalising its interpretations. Studies focusing on the clinical or psychiatric sequelae of the Holocaust may overlook the adaptive powers and coping strategies of the 
Holocaust survivors and their offspring, whereas studies limited to the description of the "normal", generalised symptoms of a difficult life may neglect the emotional costs of the adaptive strategies.

The authors of this paper represent the various scientific orientations that have been employed to unravel the psychological aftermath of the Holocaust. Despite the divergence in methods, we were able to present and discuss a number of common themes and findings. From a methodological perspective, the use of multiple methods by multiple researchers may compensate for the specific weaknesses of each individual approach. Our confidence in the conclusions increases with the convergence of the findings from the separate studies. In fact, this is the principle of "multiple triangulation" (Cook \& Campbell, 1979). Attachment theory proves to be rather useful as a framework for interpretation of the common findings. First, attachment theory allows the integration of the phenomena of attachment, separation, and loss, which appear to be core concepts in the three studies. For example, many of the Holocaust survivors experienced separation and loss of important attachment figures, inducing heightened levels of anxieties in their personal lives, as well as in the raising of their own children. The notion of insecure-ambivalent attachment shed some light on the observed preoccupation with issues of attachment and separation in the second generation. Second, attachment theory transcends the traditional boundaries between clinical and nonclinical interpretations, in stressing the continuous and cumulative nature of favourable and unfavourable child-rearing circumstances. In this context, insecure attachment is not only considered to be a risk factor in the development of psychopathology, but it should also be conceived as the best adaptive strategy in suboptimal child-rearing environments.

In sum, we believe we have proposed a fruitful paradigm for the evaluation and study of inter-generational transmission of Holocaust experiences. This paradigm has inspired the development of a new systematic quasiexperimental study, using multiple methods with nonclinical participants. The study is currently underway in Israel (carried out by authors Sagiand Van IJzendoorn jointly with Klaus Grossmann), assessing more directly, retrospectively as well as prospectively, our attachment-related conceptualisations of the transmission of Holocaust experiences across three generations-grandmothers (Holocaust child survivors), their daughters (now mothers), and their young grandchildren. In particular, the study examines the extent to which the potentially traumatising experiences of the first generation are differentially distributed. For example, although all child survivors were exposed to great trauma and severe disruption of primary relationships, they may have had very different experiences of access to substitute caregivers. Even in the death camps, adults were concerned with 
and tried to care for children. In the new study, child survivors are asked about the existence of protective relationships with caring adults before, during, and after their Holocaust experiences. In this respect, the age of the first generation during their Holocaust experiences may also be important. The younger the child, the more likely that an adult (or series of adults) would take on the caregiver role, so younger children may have been more buffered from the experiences. Furthermore, in terms of the consequences of these experiences on parenting, it seems useful to distinguish between two aspects. The first is children's direct exposure to the symptoms of parents' traumanightmares, psychotic breakdowns, crying, depression, preoccupation. These experiences may be frightening for the child, in particular when no other caregiver is there to deal directly with the adult's symptoms (in which case the child must take over), and when no other attachment figure is available to buffer the psychological experience of the child. Again, it seems that the second generation would have experienced these problems differentially. In some families, no direct breakdowns might have occurred, and in others children would not be present or not be expected to deal with them. The second, more general effect on the first generation, would be an assault on assumptive beliefs that the world is a dangerous and untrustworthy place, that valuable people can disappear at any moment, and that one's power to influence events is very limited.

The new study addresses some of the central issues concerning adaptive and maladaptive responses to major traumas like the Holocaust from an attachment perspective.

Manuscript received July 1997 Revised manuscript received December 1997

\section{REFERENCES}

Ainsworth, M.D.S., Blehar, M.C., Waters, E., \& Wall, S. (1978). Patterns of attachment: A psychological study of the Strange Situation. Hillsdale, NJ: Erlbaum.

Ainsworth, M.D.S., \& Eichberg. (1991). Effects on infant-mother attachment of mother's unresolved loss of an attachment figure or other traumatic experience. In P. Marris, J. Stevenson-Hinde, \& C. Parkes (Eds.), Attachment across the life cycle (pp. 160-183). New York: Routledge.

Barocas, H.A., \& Barocas, C. (1980). Separation-individuation conflicts in children of Holocaust survivors. Journal of Contemporary Psychotherapy, 11, 6-14.

Bar-On, D. (1995). Fear and hope: Three generations and the Holocaust. Cambridge, MA: Harvard University Press.

Benoit, D., \& Parker, K.C.H. (1994). Stability and transmission of attachment across three generations. Child Development, 65, 1444-1456.

Bowlby, J. (1951). Maternal care and mental health. Geneva: WHO.

Bowlby, J. (1973). Attachment and Loss: Vol. 2: Separation: Anxiety and Anger. New York: Basic Books.

Bowlby, J. (1984). Violence in the family as a disorder of the attachment and caregiving systems. American Journal of Psychoanalysis, 44, 9-27. 
Brom, D., Kfir, R., \& Dasberg, H. (1994). A controlled double-blind study of the offspring of Holocaust survivors. Paper presented at the Annual Conference of the Society of Traumatic Stress Studies, Chicago, IL.

Brom, D., Kleber, R.J., \& Hofman, M.C. (1993). Victims of traffic accidents: Incidence and prevention of posttraumatic stress disorder. Journal of Clinical Psychology, 49, 131-140.

Carlson, V., Cicchetti, D., Barnett, D., \& Braunwald, K. (1989). Disorganized/disoriented attachment relationships in maltreated infants. Developmental Psychology, 25, 525-531.

Cook, T.D., \& Campbell, D.T. (1979). Quasi-experimentation: design and analysis issues for field settings. Chicago: Rand McNally.

Crittenden, P. (1992). Quality of attachment in the preschool years. Development and Psychopathology, 4, 209-242.

Crowell, J.A., \& Feldman, S.S. (1988). Mothers' internal models of relationships and children's behavioral and developmental status: A study of mother-child interactions. Child Development, 59, 1273-1285.

Danieli, Y. (1980). Families of survivors of the Nazi Holocaust: Some long and short term effects. In N. Milgram (Ed.), Psychological stress and adjustment in time of war and peace. Washington: Hemisphere Publication Corporation.

Dasberg, H. (1987). Psychological distress of Holocaust survivors and offspring in Israel, forty years later: A review. Israel Journal of Psychiatry Journal, 24, 243-256.

Dor-Shav, N.K. (1978). On the long-range effects of concentration camp internment of Nazi victims. Journal of Consulting and Clinical Psychology, 46, 1-11.

Eland, J., Van der Velden, P.G., Kleber, R.J., \& Steinmetz, C.H.D. (1990). Tweede generatie Joodse Nederlanders: een onderzoek naar de gezinsachtergronden en psychisch functioneren [Second generation Jews in The Netherlands]. Deventer: Van Loghum Slaterus.

Felsen, I., \& Erlich, H.S. (1990). Identification patterns of offspring of Holocaust survivors with their parents. American Journal of Orthopsychiatry, 60, 506-520.

Fonagy, P., Steele, H., \& Steele, M. (1991). Maternal representations of attachment during pregnancy predict the organization of infant-mother attachment at one year of age. Child Development, 62, 891-905.

Frye, J.S., \& Stockton, R.A. (1982). Discrimination analysis of PTSD among a group of Vietnam veterans. American Journal of Psychiatry, 139, 52-56.

George, C., Kaplan, N., \& Main, M. (1985). Adult Attachment Interview. Unpublished manuscript, University of California, Berkeley.

Goldstein, G., Van Kammen, W., Shelly, C., Miller, D., \& Van Kammen, D. (1987). Survivors of imprisonment in the Pacific Theater during World War II. American Journal of Psychiatry, $144,1210-1214$.

Grossmann, K.E. (1986). From ideographic approaches to nomothetic hypotheses. In J. Valsiner (Ed.), The individual subject and scientific psychology (pp. 37-69). New York: Plenum.

Grossmann, K., Fremmer-Bombik, E., Rudolph, J., \& Grossmann, K.E. (1988). Maternal attachment representations as related to patterns of infant-mother-attachment and maternal care during the first year. In R.A. Hinde \& J. Stevenson-Hinde (Eds.), Relations between relationships within families (pp. 241-260). Oxford, UK: Clarendon Press.

Keilson, H. (1992). Sequential traumatization among Jewish orphans. Jerusalem: Magnes.

Kestenberg, J.S. (1972). Psychoanalytic contributions to the problems of children of survivors from Nazi persecution. Israel Journal of Psychiatry, 10, 311-325.

Kestenberg, J.S. (1980). Psychoanalyses of children of survivors from the holocaust: Case presentations and assessment. Journal of the American Psychoanalytic Association, 28, 775-804.

Kleber, R.J. (1995). Epilogue: towards a broader perspective of traumatic stress. In R.J. Kleber, C.R. Figley, \& B.P.R. Gersons (Eds.), Beyond trauma: Cultural and societal dimensions (pp. 299-306). New York: Plenum. 
Kleber, R.J., Figley, C.R., \& Gersons, B.P.R. (Eds.) (1995). Beyond trauma: Cultural and societal dimensions. New York: Plenum.

Klein,H. (1973). Children of the Holocaust: Mourning and bereavement. In E. Anthony \& C. Koupernick (Eds.), The child and his family: The impact of disease and death. New York: Wiley.

Lavie, P., \& Kaminer, H. (1991). Dreams that poison sleep: Dreaming in Holocaust survivors. Dreaming: Journal of the Association for the Study of Dreams, 1, 11-21.

Leon, G.R., Butcher, J.N., Kleinman, M., Goldberg, A., \& Almagor, M. (1981). Survivors of the Holocaust and their children: Current status and adjustment. Journal of Personality and Social Psychology, 41, 503-516.

Lifton, R.J. (1980). On the consciousness of holocaust. Psychohistory Review, 9, 3-22.

Main, M. (1990). Cross-cultural studies of attachment organization: Recent studies, changing methodologies, and the concept of conditional strategies. Human Development, 33, 48-61.

Main, M. (1996). Introduction to the special section on attachment and psychopathology overview of the field of attachment. Journal of Consulting and Clinical Psychology, 64, 237-243.

Main, M., \& Goldwyn, R. (1996). Adult Attachment Classification System, Unpublished manuscript, University of California, Berkeley.

Main, M., \& Hesse, E. (1990). Parents' unresolved traumatic experiences are related to infant disorganized attachment status: Is frightened and/or frightening parental behavior the linking mechanism? In M. Greenberg, D. Cicchetti, \& M. Cummings (Eds.), Attachment in the preschool years: Theory, research, andintervention (pp. 161-182). Chicago, IL: University of Chicago Press.

Main, M., Kaplan, N., \& Cassidy, J. (1985). Security in infancy, childhood, and adulthood: A move to the level of representation. In I. Bretherton \& E. Waters (Eds.), Growing points of attachment theory and research. Monographs of the Society for Research in Child Development, 50, (1-1, Serial No. 209), 66-106.

Main, M., \& Solomon, J. (1990). Procedures for identifying infants as disorganized/ disoriented during the Ainsworth Strange Situation. In M.T. Greenberg, D. Cicchetti, \& E.M. Cummings (Eds.), Attachment in the preschool years: Theory, research, and intervention (pp. 121-160). Chicago, IL: University of Chicago Press.

McFarlane, A.C.M. (1995). The severity of the trauma: Issues about its role in posttraumatic stress disorder. In R.J. Kleber, C.R. Figley, \& B.P.R. Gersons (Eds.), Beyond trauma: Cultural and societal dimensions (pp. 31-54). New York: Plenum.

Niederland, W.G. (1968). Clinical observations on the "survivor syndrome": Symposium on psychic traumatization through social catastrophe. International Journal of Psychoanalysis, 49, 313-315.

Parkes, C.M. (1991). Attachment, bonding, and psychiatric problems after bereavement in adult life. In C.M. Parkes, J. Stevenson-Hinde, \& P. Marris (Eds.), Attachment across the life cycle (pp. 268-292). London: Tavistock/Routledge.

Peskin, H. (1981). Observations on the first international conference on children of Holocaust survivors. Family Processes, 20, 391-394.

Radojevic, M. (1992, July). Predicting quality of infant attachment to father at 15 months from pre-natal paternal representations of attachment: An Australian contribution. Paper presented at the 25th International Congress of Psychology, Brussels, Belgium.

Raphael, B. (1986). When disaster strikes: How individuals and communities cope with catastrophe. New York: Basic Books.

Rieck, M. (1994). The psychological state of Holocaust survivors' offspring: An epidemiological and psychodiagnostic study. International Journal of Behavioral Development, 17, 649-667.

Rieck, M., \& Eitinger, L. (1983). Controlled psychodiagnostic studies of survivors of the Holocaust and their children. Israel Journal of Psychiatry, 20, 312-324. 
Rose, S.L., \& Garske, J. (1987). Family environment, adjustment, and coping among children of Holocaust survivors: A comparative investigation. American Journal of Orthopsychiatry, 57, 332-344.

Rosenheck, R., \& Nathan, P. (1985). Secondary traumatization in the children of Vietnam veterans with posttraumatic stress disorder. Hospital and Community Psychiatry, 36, 538-539.

Schuengel, C., Bakermans-Kranenburg, M.J., Van IJzendoorn, M.H., \& Blom, M. (1997, April). Attachment and loss. Frightening maternal behavior linking unresolved loss and disorganized infant attachment. Paper presented at the biennial meeting of the Society for Research on Child Development, Washington, DC.

Segev, T. (1992). The seventh million [In Hebrew]. Jerusalem: Keter.

Sigal, J.J., \& Weinfeld, M. (1987). Mutual involvement and alienation in families of Holocaust survivors. Psychiatry, 50, 280-288.

Silver, R.L., \& Wortman, C.B. (1980). Coping with undesirable events. In J. Garber \& M.E. Seligman (Eds.), Human helplessness: Theory and application. New York: Academic Press.

Solkoff, N. (1992). Children of survivors of the Nazi Holocaust: A critical review of the literature. American Journal of Orthopsychiatry, 62, 342-358.

Solomon, Z., Garb, R., Bleich, A., \& Grupper, D. (1987). Reactivation of combat-related post traumatic stress disorder. American Journal of Psychiatry, 144, 51-55.

Solomon, Z., Kotler, M., \& Mikulincer, M. (1988). Combat-related posttraumatic stress disorder among second-generation Holocaust survivors: Preliminary findings. American Journal of Psychiatry, 145, 865-868.

Solomon, Z., Oppenheimer, B., Elizur, Y., \& Waysman, M. (1990). Exposure to recurrent combat stress: Can successful coping in a second war heal combat-related PTSD from the past? Journal of Anxiety Disorders, 4, 141-145.

Solomon, Z., \& Prager, E. (1992). Elderly Israeli holocaust survivors during the Persian Gulf War: A study of psychological distress. American Journal of Psychiatry, 149, 1707-1710.

Van IJzendoorn, M. (1995). Adult attachment representations, parental responsiveness, and infant attachment: A meta-analysis on the predictive validity of the Adult Attachment Interview. Psychological Bulletin, 117, 387-403.

Thienes-Hontos, P., Watson, Ch.G., \& Kucala, T. (1982). Stress-disorder symptoms in Vietnam and Korean War veterans. Journal of Consulting and Clinical Psychology, 50, 558-561.

Ward, M.J., \& Carlson, E.A. (1995). Associations among adult attachment representations, maternal sensitivity, and infant-mother attachment in a sample of adolescent mothers. Child Development, 66, 69-79.

Wardi, D. (1990). The memorial candles: Dialogues with children of Holocaust survivors. Jerusalem: Keter (in Hebrew).

Weiss, E., O’Connell, A.N., \& Siiter, R. (1986). Comparisons of second-generation holocaust survivors, immigrants, and nonimmigrants on measures of mental health. Journal of Personality and Social Psychology, 50, 828-831.

Yablonka, C. (1990). The problem of absorption of Holocaust survivors in the emerging Israeli society. Unpublished doctoral dissertation, Hebrew University, Jerusalem. 